\title{
Signature Authentication using Deep Learning
}

\author{
S. Sangeetha, S. Pothumani, K. Anita Davamani
}

\begin{abstract}
This paper depicts the strategy to confirm marks utilizing profound learning. The paper covers the different modules and the design required to accomplish the reason. Convolutional neural systems are actualized to parse marks and feed forward neural systems are executed to investigate the attributes of the mark. Angle plummet is utilized to address mistakes with a technique got back to spread. This paper discusses how the mark on the check is contrasted with the mark in the database and how a last verification score is given to the client.
\end{abstract}

Keywords : Machine learning, Deep learning, Neural networks, Convolution, Pooling, Activation function, ReLU, Gradient Descent, Training, Test, Validation.

\section{INTRODUCTION}

Machine learning is the possibility that there are nonexclusive calculations that can give intriguing data about a lot of information without composing any custom code explicit to the issue. Information is nourished into the conventional calculation and the rationale is assembled dependent on the information. Machine learning can be utilized in a few fields like picture arrangement, discourse acknowledgment, cybersecurity, mechanical autonomy and so on. Profound learning is the theme that covers neural systems and is a piece of machine learning.

A neural system is a computational model that works comparatively to the neurons in the human mind. Every neuron takes an info, plays out a few activities at that point passes the yield to the accompanying neuron. For picture grouping, Convolutional Neural Networks (CNN) are utilized. CNNs are basically utilized for picture handling however can likewise be utilized for different sorts of info, for example, sound. A run of the mill use case for CNNs is the place you feed the system pictures and the system groups the information[1],[3],[5]

The informational collection is separated into three sections. Preparing information, testing information and approval information. Preparing information is utilized to prepare a multi-layer perceptron. The following stage is to discover how well it performs. On account of prepared system the blunder can be registered by processing the total of squares mistake among yield and target. The subsequent stage is to

Revised Manuscript Received on July 22, 2019.

S. Sangeetha, Department of CSE, Bharath Institute of Higher Education and Research, Chennai, Tamilnadu, India. Email:sangeethasathya01@gmail.com

S. Pothumani, Department of CSE, Bharath Institute of Higher Education and Research, Chennai,, India Email: pothumani@gmail.com

Ms. K. Anita Davamani, Department of CSE, Bharath Institute of Higher Education and Research, Chennai,, India.Email: anitadavamani@gmail.com

make sense of which information ought to be utilized to test the system. It isn't insightful to utilize

indistinguishable information for preparing from well as testing, since it would not know how well the system sums up and regardless of whether the model overfit the information. Consequently we have to keep separate matches for possible later use for test set (input, target) which are not utilized for preparing reason. This kind of informational collection is called as test informational index[2 ],[4],[6]

We check how well the system is getting the hang of amid preparing, so we can choose when to quit preparing the model[7],[9] ,[11]. To take such a choice, we can't utilize preparing information as we would not recognize overfitting but rather we can't utilize the testing information either as we are sparing it for conclusive test. In this way the third sort of informational index called approval set is required to approve the adapting up until now. In measurements it is known as cross approval[8],[10],[12]. On the off chance that there is a tremendous measure of information, the careful extent of preparing to testing to approval information is some place around 50:25:25 and in the event of less measure of information it is 60:20:20.

CNNs will in general begin with an information scanner. The scanner filters the info picture and passes it on to the following layer. This information is then sustained through convolutional layers[13], [15],[ 17]. These convolutional layers additionally will in general therapist as they end up further, for the most part by effectively separable variables of the info. Other than these convolutional layers, they likewise frequently include pooling layers[14],[ 16], [18]. Pooling is an approach to sift through subtleties: a regularly discovered pooling strategy is max pooling, which takes $2 \times 2$ pixels and passes on the pixel with the greatest esteem.

The yield of the CNN goes about as the contribution for a completely associated layer where the highlights of the picture are set up[19],[21],[23]. The completely associated layer is a feed forward neural system with numerous shrouded layers. The attributes of the mark like spots, dashes and bends are set up in every one of the shrouded layers, which are then passed on to the following layer for preparing. The yield of the completely associated layer is the arrangement of the mark.

\section{PROPOSED SYSTEM}

My work includes confirming the mark on a check by filtering the check and utilizing machine learning model on the examined picture. Convolutional neural systems (CNN)

Published By: 
and Feed Forward neural systems are utilized to achieve the above errand.

The initial phase in the process is to include the filtered picture of the check to a CNN. A scanner or a channel checks the picture and the contribution of the scanner is then passed on to the following layer. The scanner is commonly a grid with an arbitrary arrangement of qualities[20],[ 22], [24]. This framework is first set on the upper left corner of the picture. A dab result of the pixel estimation of the picture and the separate an incentive on the network is determined. The yield of the scanner is a lot of channels (the extent of this set shifts with the quantity of scanners). This procedure can be rehashed commonly to build exactness. The yield of the last convolutional layer is then bolstered into a feed-forward neural system.

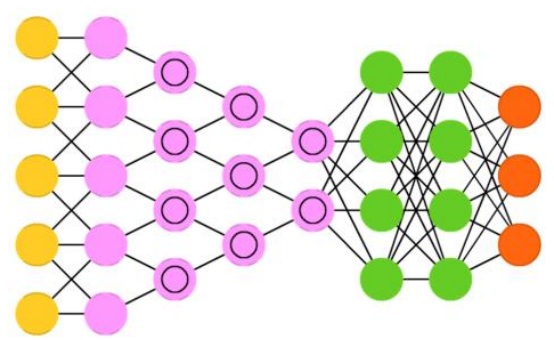

Representation of a convolutional neural network

When the scanner examines the picture, a pooling capacity is utilized to feature the most imperative parts of the picture and to lessen the span of the picture.

Pooling layer is every now and again utilized in convolutional neural systems with the reason to dynamically lessen the spatial size of the portrayal, to diminish the measure of highlights and the computational multifaceted nature of the system. The more ordinarily utilized pooling layer is the maxpool layer. A maxpool of $2 \times 2$ would reason a channel of 2 by 2 to navigate over the whole network and pick the biggest component from the window to be incorporated into the following portrayal map.

In this way, successfully the elements of the component map diminish from $(\mathrm{m}, \mathrm{n})$ to $(\mathrm{m} / \mathrm{k}, \mathrm{n} / \mathrm{k})$ on utilization of a $(\mathrm{k}, \mathrm{k})$ non-covering channel. Thus, $\mathrm{k}$ should be picked in consistence with the elements of the information highlight map. Interestingly, the measurements on use of a convolution layer would move to $(\mathrm{m}-\mathrm{k}+1, \mathrm{n}-\mathrm{k}+1)$. Not at all like the convolution layer, the pooling channel does not work on covering portions of the info include map. Be that as it may, we can expressly determine the walk to make the task covering. The pooling can be actualized in different ways moreover.

The principle purpose behind utilizing the pooling layer is to keep the model from overfitting. In a significant number models, the dropout layer succeeds the pool.

It is imperative to be watchful in the utilization of the pooling layer, especially in vision assignments. While it would help essentially lessen the multifaceted nature of the model, area affectability may be lost.
Consider for example a dream assignment that includes recognizing a ball in a picture[25],[27],[29]

. Utilizing the pooling layer is useful in the event that we are to decide whether the ball exists in the picture or not. Be that as it may, if the assignment is worried about deciding the accurate area of the ball in the picture also, we should be somewhat watchful with respect to utilizing a pooling layer.

In this way the pooling layer is essentially utilized for decreasing the computational multifaceted nature of the model. We can like to utilize it in situations where we can stand to lose some localisation data. Pooling is really intriguing and regular to use in profound learning models.

Once the convolutional step is finished, the yield goes through an enactment work that acquaints some nonlinearity with the capacity[26],[28],[30]. There are a few initiation capacities, for example, Identity, Heaviside, sigmoid, tanh and ReLU. For this issue, a Rectified Linear unit or ReLU is utilized.

The ReLU is the most utilized initiation work, since it is utilized in all the convolutional neural systems or profound learning. The capacity and its subsidiary both are monotonic. The issue is that all the negative qualities end up zero quickly which diminishes the capacity of the model to fit or prepare from the information legitimately. That implies, any negative info given to the ReLU initiation work transforms the incentive into zero quickly in the chart, which in turns influences the subsequent diagram by not mapping the negative qualities properly. Another variety of ReLU is cracked ReLU. It deals with the negative qualities to some degree.

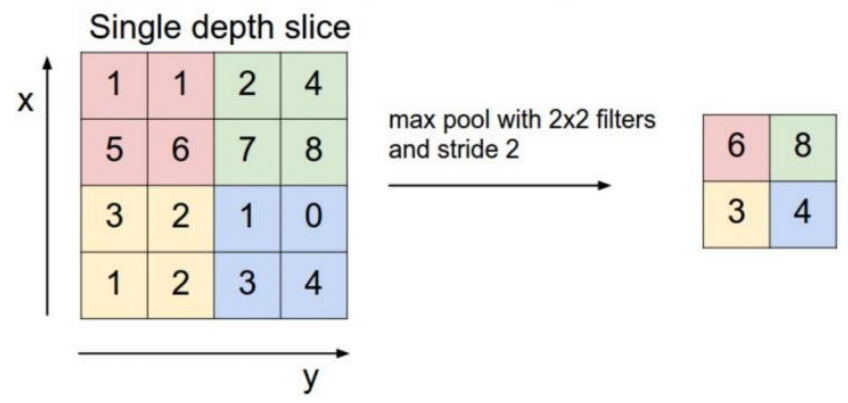

ReLU trains multiple times quicker than tanh. Likewise, ReLU addresses the evaporating slope issue with sigmoid and tanh capacities don't. The yield estimation of ReLU will be zero when the info esteem is under zero. In the event that the info is more noteworthy than or equivalent to zero, at that point the yield is equivalent to the information. At the point when the information esteem is sure, the subordinate is 1 . Henceforth there will be no pressing impact which happens on account of back-proliferating mistakes from the sigmoid capacity.

The Feed Forward neural system is a lot of neurons of different layers beginning with the info layer and completion with the yield layer. All layers in the middle of are called shrouded layers[31],[33],[35]. Expanding the quantity of concealed layers, builds the proficiency of the neural system however will likewise 
require higher preparing capacity to figure.

In the Feed Forward neural system, the qualities of the mark, for example, the bends, dashes, and specks are dissected. The yield of the Feed Forward neural system is a characterization of that signature.

The system is first prepared on a preparation set and after that tried on a testing set. When the system is prepared, new sources of info can be given to the system for characterization. At the point when the system has first prepared, the blunder is high. To bring down the blunder, streamlining is connected to the neural system. Improving is conceivable with a procedure called angle plummet, where the anticipated yield is contrasted and the real yield and after that the loads are changed in accordance with get an esteem that will diminish the blunder.

First Order Optimization Algorithms - These calculations limit or augment a Loss work $\mathrm{E}(\mathrm{x})$ utilizing its Gradient esteems as for the parameters. Most broadly utilized First request advancement calculation is Gradient Descent. The First request subsidiary discloses to us whether the capacity is diminishing or expanding at a specific

\section{SYSTEM ARCHITECTURE}

$$
f(x)=\left\{\begin{array}{lll}
0 & \text { for } & x<0 \\
x & \text { for } & x \geq 0
\end{array}\right.
$$

ReLU activation function

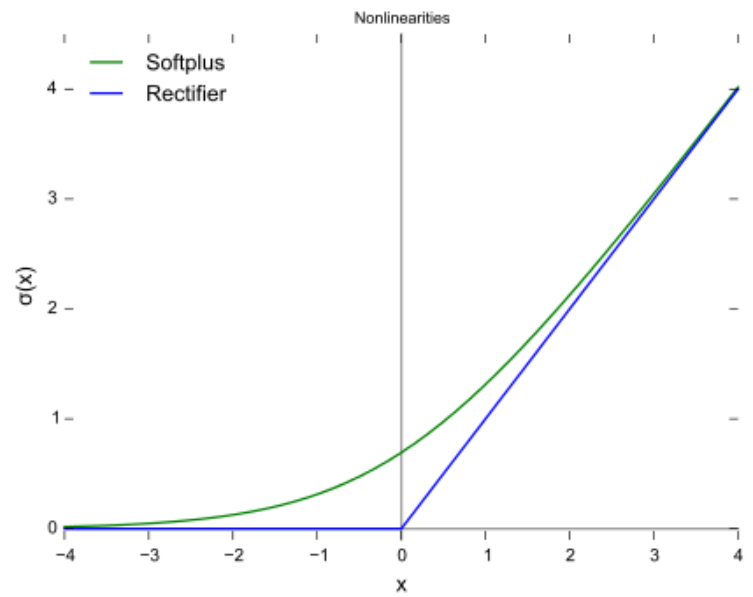

Graphical representation of $\operatorname{ReLU}$
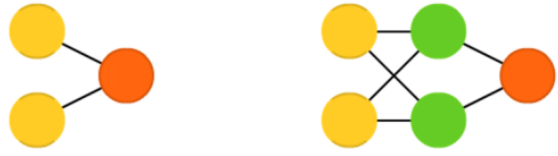

Representation of a feed-forward neural network

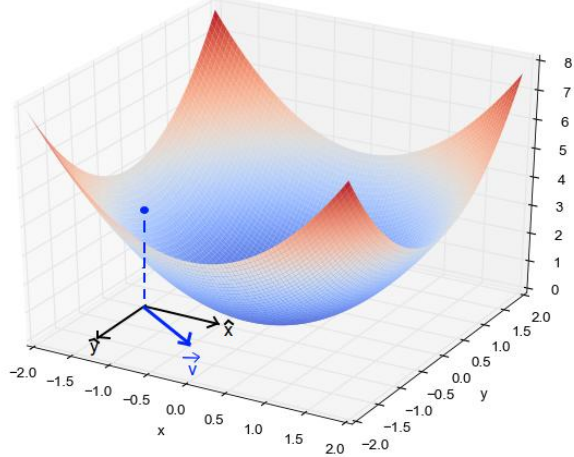

Representation of gradient descent

The client transfers the filtered duplicate of the mark

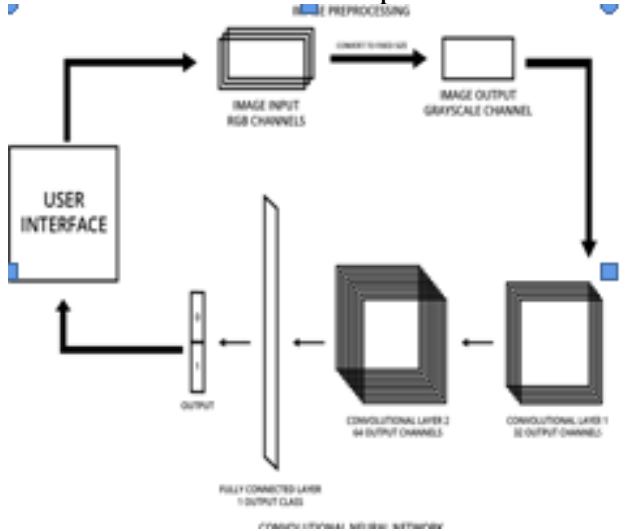

through the UI. The checked picture preprocessed in the preprocessing step. The RGB channels are changed over into Grayscale channel. The span of each picture is changed over into 70 X 150 units.

The prepared picture is then sent as a contribution to the first convolutional layer. This layer changes over the contribution to 32 channels by passing a picture channel through the information. This is at that point

sent to a maximum pool layer which separates just the most vital highlights of the picture. The yield of the primary layer is then sent to the second convolutional layer. This layer accepts the 32 channels as the info layer and yields 64 channels. This is likewise gone through a maximum pool layer. The yield of the second layer is then passed as a solitary dimensional exhibit through a completely associated neural system. This system at that point yields the exactness rate.

The neural system likewise comprises of a completely associated layer. The completely associated layer presents he validation score to the UI. [32],[34],[36]

The client transfers the filtered duplicate of the mark through the UI. The checked picture preprocessed in the preprocessing step. The RGB channels are changed over into Grayscale channel. The span of each picture is changed over into $70 \times 150$ units.

The prepared picture is then sent as a contribution to the first convolutional layer. This layer changes over the contribution to 32 channels by passing a picture channel through the 
information. This is at that point

sent to a maximum pool layer which separates just the most vital highlights of the picture. The yield of the primary layer is then sent to the second convolutional layer. This layer accepts the 32 channels as the info layer and yields 64 channels. This is likewise gone through a maximum pool layer[37],[39],[41]. The yield of the second layer is then passed as a solitary dimensional exhibit through a completely associated neural system. This system at that point yields the exactness rate.

unit channel. The neural system likewise comprises of a completely associated layer[38],[40],. The completely associated layer presents he validation score to the UI.

\section{MODULES}

\section{MODULE 1: USER INTERFACE}

The User interacts with the program using the command prompt which serves as the user interface for input and output.

\section{MODULE 2: IMAGE PREPROCESSING}

The images are stored at a particular address. All the images for the training and testing purposes pass through this module. The images are converted to a specific format in this module.

\section{MODULE 3: NEURAL NETWORK}

The neural network takes the image as input and outputs a score. The neural network consists of two convolutional layers with 5 X 5 unit filter. The neural network also consists of a fully connected layer. The fully connected layer presents he authentication score to the user interface.

\section{OUTPUT}

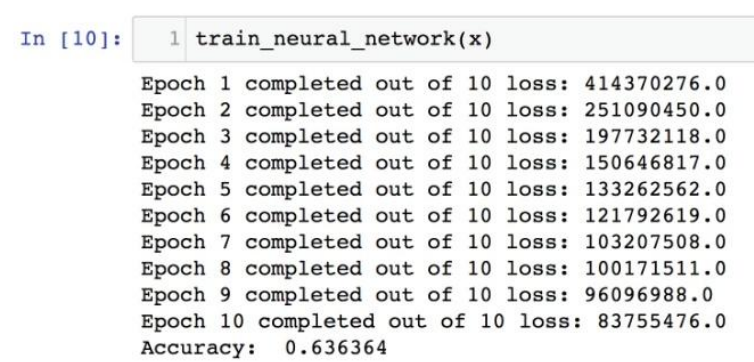

V. CONCLUSION

Machine learning is being embraced by numerous individuals of the enterprises world over, particularly the monetary division. My work is an endeavor to supplement the endeavors done here. My model will help decrease the quantity of fake exchanges in the managing an account industry by giving an exact assessment of the mark in the archives. This will help in lessening the misfortunes acquired by banks. It will likewise help in achieving fast turnaround times by radically cutting the manual intercession. The

expense of usage of the machine learning model is low and the versatility of the model is high. The ongoing upgrades in Convolutional neural systems is the making of another model called Capsule Networks where every neuron will hold a settled neural system. With the Capsule Network, another actuation work is likewise being created, which can deliver better outcomes. With the headway of machine learning models and enhanced computational forces, the exactness of the machine learning models increment a far cry and the pivot time is decreased severalfold.

\section{REFERENCES}

[1] Kumaravel A., Rangarajan K.,Algorithm for automaton specification for exploring dynamic labyrinths,Indian Journal of Science and Technology,V-6,I-SUPPL5,PP-4554-4559,Y-2013

[2] P. Kavitha, S. Prabakaran "A Novel Hybrid Segmentation Method with Particle Swarm Optimization and Fuzzy C-Mean Based On Partitioning the Image for Detecting Lung Cancer" International Journal of Engineering and Advanced Technology (IJEAT) ISSN: 2249-8958, Volume-8 Issue-5, June 2019

[3] Kumaravel A., Meetei O.N.,An application of non-uniform cellular automata for efficient cryptography,2013 IEEE Conference on Information and Communication Technologies, ICT 2013,V-,I-,PP-1200-1205,Y-2013

[4] Kumarave A., Rangarajan K.,Routing alogrithm over semi-regular tessellations,2013 IEEE Conference on Information and Communication Technologies, ICT 2013,V-,I-,PP-1180-1184,Y-2013

[5] P. Kavitha, S. Prabakaran "Designing a Feature Vector for Statistical Texture Analysis of Brain Tumor" International Journal of Engineering and Advanced Technology (IJEAT) ISSN: 2249-8958, Volume-8 Issue-5, June 2019

[6] Dutta P., Kumaravel A.,A novel approach to trust based identification of leaders in social networks,Indian Journal of Science and Technology,V-9,I-10,PP--,Y-2016

[7] Kumaravel A., Dutta P.,Application of Pca for context selection for collaborative filtering,Middle - East Journal of Scientific Research,V-20,I-1,PP-88-93,Y-2014

[8] Kumaravel A., Rangarajan K.,Constructing an automaton for exploring dynamic labyrinths,2012 International Conference on Radar, Communication and Computing, ICRCC 2012,V-,I-,PP-161-165,Y-2012

[9] P. Kavitha, S. Prabakaran "Adaptive Bilateral Filter for Multi-Resolution in Brain Tumor Recognition" International Journal of Innovative Technology and Exploring Engineering (IJITEE) ISSN: 2278-3075, Volume-8 Issue-8 June, 2019

[10] Kumaravel A.,Comparison of two multi-classification approaches for detecting network attacks,World Applied Sciences Journal,V-27,I-11,PP-1461-1465,Y-2013

[11] Tariq J., Kumaravel A.,Construction of cellular automata over hexagonal and triangular tessellations for path planning of multi-robots,2016 IEEE International Conference on Computational Intelligence and Computing Research, ICCIC 2016,V-,I-,PP--,Y-2017

[12] Sudha M., Kumaravel A.,Analysis and measurement of wave guides using poisson method,Indonesian Journal of Electrical Engineering and Computer Science, V-8,I-2,PP-546-548,Y-2017

[13] Ayyappan G., Nalini C., Kumaravel A.,Various approaches of knowledge transfer in academic social network,International Journal of Engineering and Technology,V-,I-,PP-2791-2794,Y-2017

[14] Kaliyamurthie, K.P., Sivaraman, K., Ramesh, S. Imposing patient data privacy in wireless medical sensor networks through homomorphic cryptosystems 2016, Journal of Chemical and Pharmaceutical Sciences92.

[15] Kaliyamurthie, K.P., Balasubramanian, P.C. An approach to multi secure to historical malformed documents using integer ripple transfiguration 2016 Journal of Chemical and Pharmaceutical Sciences92. 
[16] A.Sangeetha,C.Nalini,"Semantic Ranking based on keywords extractions in the web", International Journal of Engineering \& Technology, 7 (2.6) (2018) 290-292

[17] S.V.GayathiriDevi,C.Nalini,N.Kumar,"An efficient software verification using multi-layered software verification tool "International Journal of Engineering \& Technology, 7(2.21)2018 $454-457$

[18] C.Nalini,ShwtambariKharabe,"A Comparative Study On Different Techniques Used For Finger - Vein Authentication", International Journal Of Pure And Applied Mathematics, Volume 116 No. 8 2017, 327-333, Issn: 1314-3395

[19] M.S. Vivekanandan and Dr. C. Rajabhushanam, "Enabling Privacy Protection and Content Assurance in Geo-Social Networks", International Journal of Innovative Research in Management, Engineering and Technology, Vol 3, Issue 4, pp. 49-55, April 2018.

[20] Dr. C. Rajabhushanam, V. Karthik, and G. Vivek, "Elasticity in Cloud Computing", International Journal of Innovative Research in Management, Engineering and Technology, Vol 3, Issue 4, pp. 104-111, April 2018.

[21] K. Rangaswamy and Dr. C. Rajabhushanamc, "CCN-Based Congestion Control Mechanism In Dynamic Networks", International Journal of Innovative Research in Management, Engineering and Technology, Vol 3, Issue 4, pp. 117-119, April 2018.

[22] Kavitha, R., Nedunchelian, R., "Domain-specific Search engine optimization using healthcare ontology and a neural network backpropagation approach", 2017, Research Journal of Biotechnology, Special Issue 2:157-166

[23] Kavitha, G., Kavitha, R., "An analysis to improve throughput of high-power hubs in mobile ad hoc network", 2016, Journal of Chemical and Pharmaceutical Sciences, Vol-9, Issue-2: 361-363

[24] Kavitha, G., Kavitha, R., "Dipping interference to supplement throughput in MANET" , 2016, Journal of Chemical and Pharmaceutical Sciences, Vol-9, Issue-2: 357-360

[25] Michael, G., Chandrasekar, A.,'Leader election based malicious detection and response system in MANET using mechanism design approach", Journal of Chemical and Pharmaceutical Sciences(JCPS) Volume 9 Issue 2, April - June 2016

[26] Michael, G., Chandrasekar, A.,"Modeling of detection of camouflaging worm using epidemic dynamic model and power spectral density", Journal of Chemical and Pharmaceutical Sciences(JCPS) Volume 9 Issue 2, April - June 2016.

[27] Pothumani, S., Sriram, M., Sridhar, J., Arul Selvan, G., Secure mobile agents communication on intranet,Journal of Chemical and Pharmaceutical Sciences, volume 9, Issue 3, Pg No S32-S35, 2016

[28] Pothumani, S., Sriram, M., Sridhar, Various schemes for database encryption-a survey, Journal of Chemical and Pharmaceutical Sciences, volume 9, Issue 3, Pg NoS103-S106, 2016

[29] Pothumani, S., Sriram, M., Sridhar, A novel economic framework for cloud and grid computing, Journal of Chemical and Pharmaceutical Sciences, volume 9, Issue 3, Pg No S29-S31, 2016

[30] Priya, N., Sridhar, J., Sriram, M. "Ecommerce Transaction Security Challenges and Prevention Methods- New Approach" 2016 ,Journal of Chemical and Pharmaceutical Sciences, JCPS Volume 9 Issue 3.page no:S66-S68

[31] Priya, N.,Sridhar,J.,Sriram, M."Vehicular cloud computing security issues and solutions" Journal of Chemical and Pharmaceutical Sciences(JCPS) Volume 9 Issue 2, April - June 2016

[32] Priya, N., Sridhar, J., Sriram, M. "Mobile large data storage security in cloud computing environment-a new approach" JCPS Volume 9 Issue 2. April - June 2016

[33] Anuradha.C, Khanna.V, "Improving network performance and security in WSN using decentralized hypothesis testing "Journal of Chemical and Pharmaceutical Sciences(JCPS) Volume 9 Issue 2, April - June 2016.

[34] Anuradha.C, Khanna.V, "A novel gsm based control for e-devices" Journal of Chemical and Pharmaceutical Sciences(JCPS) Volume 9 Issue 2, April - June 2016.

[35] Anuradha.C, Khanna.V, "Secured privacy preserving sharing and data integration in mobile web environments " Journal of Chemical and Pharmaceutical Sciences(JCPS) Volume 9 Issue 2, April - June 2016.

[36] Sundarraj, B., Kaliyamurthie, K.P. Social network analysis for decisive the ultimate classification from the ensemble to boost accuracy rates 2016 International Journal of Pharmacy and Technology
[37] Sundarraj, B., Kaliyamurthie, K.P. A content-based spam filtering approach victimisation artificial neural networks 2016 International Journal of Pharmacy and Technology83.

[38] Sundarraj, B., Kaliyamurthie, K.P. Remote sensing imaging for satellite image segmentation 2016 International Journal of Pharmacy and Technology8 3.

[39] Sivaraman, K., Senthil, M. Intuitive driver proxy control using artificial intelligence 2016 International Journal of Pharmacy and Technology 84 .

[40] Sivaraman, K., Kaliyamurthie, K.P. Cloud computing in mobile technology 2016 Journal of Chemical and Pharmaceutical Sciences 92 .

[41] Sivaraman, K., Khanna, V. Implementation of an extension for browser to detect vulnerable elements on web pages and avoid click jacking 2016 Journal of Chemical and Pharmaceutical Sciences92.

\section{AUTHORS PROFILE}

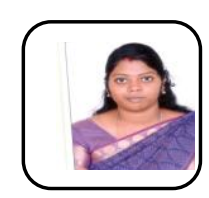

S. Sangeetha Assistant Professor, Department of Computer Science \& Engineering, Bharath Institute of Higher Education and Research, Chennai, India

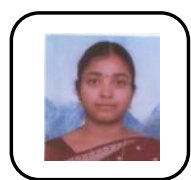

S. Pothumani Assistant Professor, Department of Computer Science \& Engineering, Bharath Institute of Higher Education and Research, Chennai, India

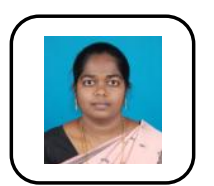

Ms. K. Anita Davamani Assistant Professor, Department of Computer Science \& Engineering, Bharath Institute of Higher Education and Research, Chennai, India 